Case Report:

\title{
Spontaneous Spinal Epidural Hematoma in a Patient With a Prosthetic Valve
}

\author{
Amir Abbas Ghasemi ${ }^{1}$, Atta Mahdkhah ${ }^{1}$, Amir Kamalifar $^{1 *}$ (D) Samar Kamalifar ${ }^{2}$
}

1. Department of Neurosurgery, School of Medicine, Nazlou Campus, Urumia University of Medical Sciences, Urumia, Iran

2. Department of Anatomy, School of Medicine, Arak University of Medical Sciences, Arak, Iran

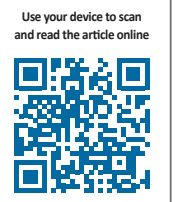

Citation Ghasemi AA, Mahdkhah A, Kamalifar A, Kamalifar S. Spontaneous Spinal Epidural Hematoma in a Patient With a Prosthetic Valve. Iran J Neurosurg. 2018; 4(1):45-50. http://dx.doi.org/10.32598/irjns.4.1.45

doi): http://dx.doi.org/10.32598/irjns.4.1.45

Funding: See Page 48

(c) Copyright: The Author(s)

Article info:

Received: 20 August 2017

Accepted: 02 November 2017

Available Online: 01 January 2018

Keywords:

Spinal epidural hematoma, Laminectomy, Prosthetic valve, Spinal cord injury

\section{ABSTRACT}

Spontaneous Spinal Epidural Hematoma (SSEH) is a rare spinal condition. Early surgical intervention is generally indicated to prevent serious permanent neurological deficits. We encountered a case of spontaneous spinal epidural hematomas associated with motor weakness that was treated successfully by surgical evacuation.

\section{Background and Importance}

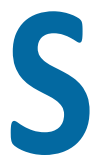

pontaneous Spinal Epidural Hematoma (SSEH) is an uncommon, but it is a disabling disease. The incidence of SSEH was estimated to be 0.1 patients per 100,000 populations per year [13]. The etiology remains unknown; however, it has been increasingly reported in patients with blood dyscrasias [4], platelet dysfunction [5], anticoagulation therapy, or thrombolysis [6]. The usual clinical presentation is acute onset of neck or back pain that progresses toward neurological dysfunction, depending on the level of the lesion [3].

Although some non-surgical treatments have been reported, prompt diagnosis and surgical evacuation of epidural clot remains the standard treatment. SSEH is relatively rare in comparison with traumatic spinal epidural hematoma. First report of SSEH published in the $1800 \mathrm{~s}$ titled "a case of spinal apoplexy" [7]. Acute cord compression occurs in $40 \%$ of all SSEH [8]. An early study showed its incidence as 0.1 per 100,000 people per year [9]. Most cases occur in persons between 50 and 80 years of age. The male to female ratio is $1.4: 1[4,10]$.

The etiology of SSEH is unclear, but anticoagulants like warfarin are reported important risk factors [6]. Recently, new oral anticoagulants, oral Factor Xa inhibitors, and oral direct thrombin inhibitors, were used for patients with atrial fibrillation and prosthetic valve $[9,11]$. Based on the study of Golparkinson and Surabbo et al. we summarizes classifi-

* Corresponding Author:

Amir Kamalifar, MD

Address: Department of Neurosurgery, School of Medicine, Nazlou Campus, Urumia University of Medical Sciences, Urumia, Iran

Tel: +98 (914) 1534548

E-mail:amirkamalifar@gmail.com 


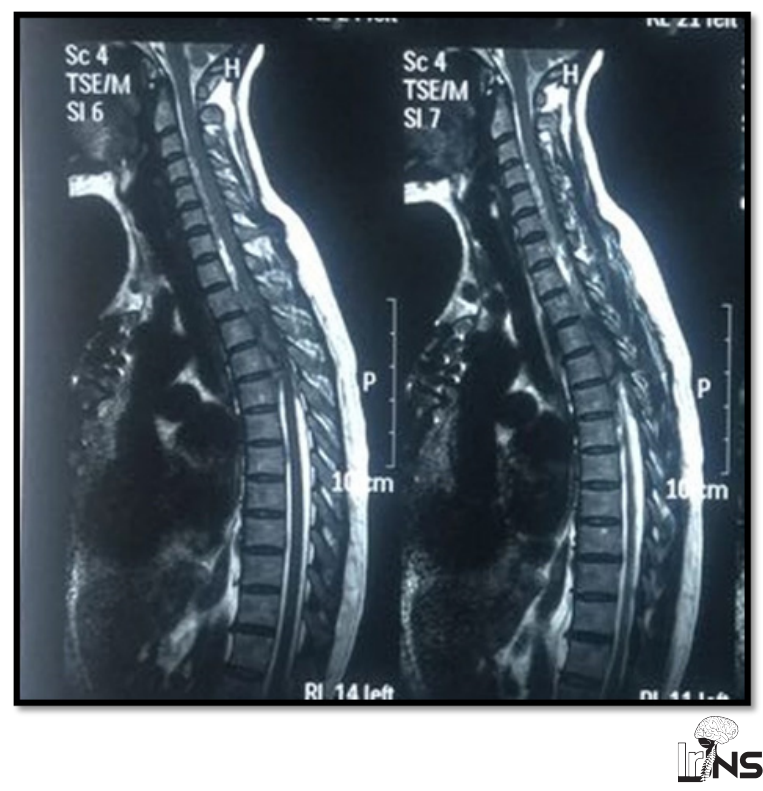

Figure 1. Sagittal T2 MR sequences showing a large mass at the level of T2-T7 and some signal changes in ventral portion of cervical spinal canal at the level of c4-c7

cation and pathophysiology and management for epidural hematoma in Table $2[12,13]$. SSEH predominantly occurs dorsal to the spinal cord of the cervico-thoracic or thoracolumbar level $[4,10,14,15]$.

The bleeding mechanism of SSEH remains unclear. Most researchers assert that it comes from the epidural venous plexus in the spinal epidural space because it lacks venous valves, and the undulating pressure from the thoracic and abdominal cavity can impact it directly [16-18]. A previous study concluded that the posterior internal vertebral venous plexus plays an important causative role in SSEH. The fact that most SSEHs develop dorsal to the spinal cord also supports the theory that posterior internal vertebral venous plexus is the main source of SSEH $[14,15]$. However, several authors have proposed the spinal epidural arteries as a source of hematoma [18]. A more likely explanation is that pressure from arterial bleeding compresses the spinal cord [16]. This paper presents a SSEP case who was treated with surgical intervention.

Table 1. Muscle strength before and after decompression surgery

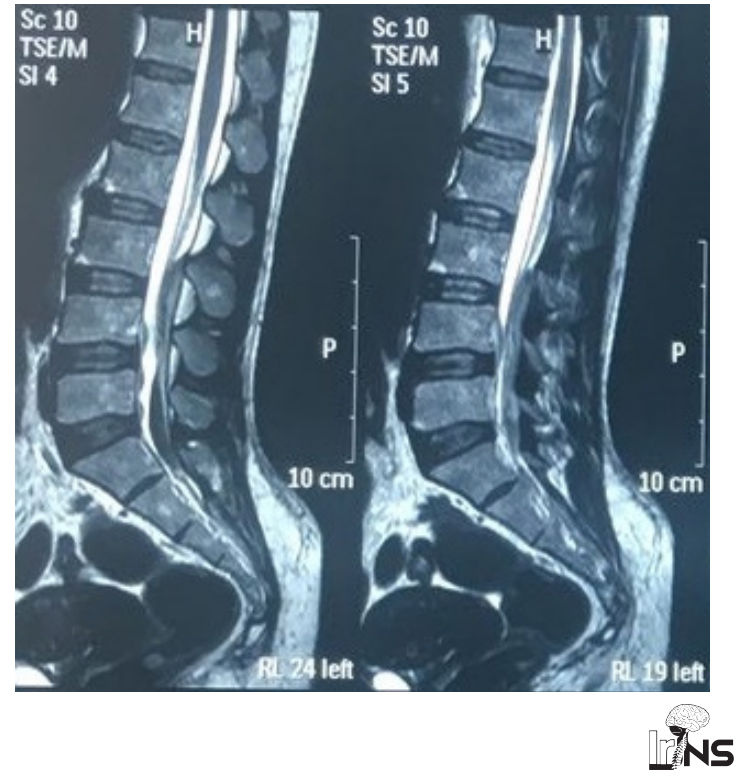

Figure 2. Sagittal and para sagittal T2 MR sequence of lumbosacral spine showing signal change in posterior portion of thecal sac at the level of L3-L5

\section{Case Presentation}

A 56 years old woman presented to the emergency department with progressive weakness of lower limbs. She had reported attack of upper back and neck pain for seven days then experienced paresthesia and weakness in lower extremities over the course of next 2-3 days. Her past medical and surgical history was significant for mitral valve replacement (9 years ago) and concurrently takes warfarin and digoxin. Physical examination was remarkable for lower extremities weakness (Table 1) with a sensory level of T8 the patient's deep tendon reflexes were increased at the patellar and Achilles tendons. Laboratory investigations were within normal limit except for Prothrombin time (INR=10.1).

MRI of the spine showed lesion typical of epidural hematoma along the length of cervical, thoracic and upper lumbar spine (Figures 1, 2, 3). Fresh Frozen Plasma was administered to the patient for coagulation abnormality. The patient was transferred to the operating room for standard laminectomy. After positioning the patient in prone position and

\begin{tabular}{cccc}
\hline Muscles Tested & Hip Flexor & Knee Extensor & Big Toe Extensor \\
Muscle Strength & 0.5 & 1.5 & 1.5 \\
\hline Before surgery & 3.5 & 3.5 & 4.5 \\
\hline After surgery & & & NS
\end{tabular}




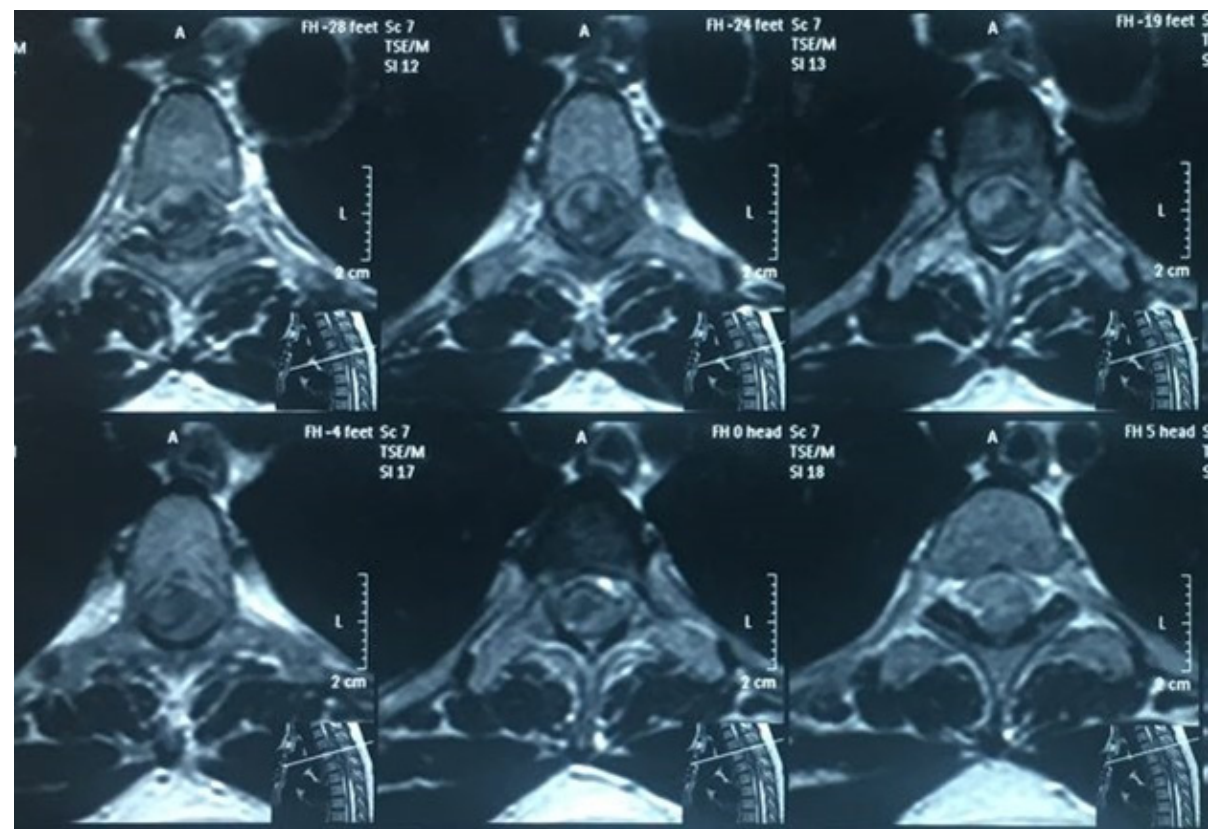

Figure 3. Axial T2 MR sequences of thoracic spine showing an epidural hematoma compressing the cord

prepping skin, an incision was done along the midline and standard laminectomy was performed mainly from T2- T7 where maximum spinal cord compression was noted. Rehabilitation program was initiated early after surgery. At the time of writing this paper, muscle strength of lower extremities has shown some improvement (Table 1).

\section{Discussion}

In the present case, the hematoma was distributed on cervical thoracic, upper lumbar, as shown by MRI. In addition, the patient showed slowly -progressed symptoms. The origin of SSEH could not be determined; these findings support

Table 2. Characteristics of spinal epidural hematoma

\begin{tabular}{|c|c|c|}
\hline \multicolumn{2}{|c|}{ Characteristics } & Description \\
\hline \multirow{3}{*}{ Classification } & Spontaneous & $\begin{array}{l}\text { Existence of a possible co-risk factor such as minor trauma, metabolic or inflamma- } \\
\text { tory bone disease involving the spine, anticoagulant and coagulopathy, }\end{array}$ \\
\hline & latrogenic & Post-open surgery, lumbar puncture, or epidural injections \\
\hline & Idiopathic & No cause or risk factors identifiable \\
\hline \multirow{3}{*}{ Time course } & Acute & Sudden neurologic deficit \\
\hline & Acute on chronic & Stepwise deterioration of neurology \\
\hline & Chronic & Progressive decline, which can mimic other pathologies such as disk disease \\
\hline \multirow[t]{2}{*}{ Pathophysiology } & $\begin{array}{c}\text { No single mechanism } \\
\text { identified for epidural } \\
\text { hematoma }\end{array}$ & Venous bleeding in spontaneous cases \\
\hline & $\begin{array}{l}\text { Without a clear } \\
\text { secondary cause }\end{array}$ & $\begin{array}{l}\text { Evidence of inflammatory/metabolic processes affecting the spinal ligaments as well } \\
\text { as bone, Leading to vessel inflammation and erosion }\end{array}$ \\
\hline $\begin{array}{l}\text { Management } \\
\text { Pathway }\end{array}$ & Deco & $\begin{array}{l}\text { Clinical assessment } \\
\text { Urgent magnetic resonance image scan } \\
\text { Reversal of any anticoagulation } \\
\text { Treatment of coagulopathy with hematology specialist input } \\
\text { mpressive surgery: emergency for acute cases with neurologic deficit } \\
\text { ous or staged specialist management of secondary causes such as vascular } \\
\text { Malformations or tumors } \\
\text { Send histologic specimens } \\
\text { Evaluation of histology postoperatively } \\
\text { Treatment of any retrospectively identified co-risk factors } \\
\text { Rehabilitation }\end{array}$ \\
\hline
\end{tabular}


that epidural vein is the bleeding source for SSEH in this case. The patient usually feels a sudden sharp and radicular low back pain. The pain maybe aggravated by percussion on the spine or maneuvers which increase the intraspinal pressure like coughing and sneezing. The patient's sensory and motor findings depend on the lesion and hematoma size that include weakness, paresis, bladder dysfunction, and sensory deficit [19] in high cervical levels, SSEH could cause spinal shock, leading to fatal condition [20].

The present patient suffered from numbness, higher back pain, and progressive paraplegia. The thickest hematoma was located at the T2 \& T7 level. Therefore, it was decided to perform the surgical treatment at the level of $\mathrm{T} 2$ to $\mathrm{T} 7$. The diagnosis and treatment of the spinal epidural hematoma are very important, as it is a potentially reversible pressure lesion on the spinal cord and roots [21]. Currently, the Magnetic Resonance Imaging (MRI) is the first diagnostic method of choice that can reveal a biconvex hematoma in the epidural space with well-defined borders. It taper towards up and down. When MRI is not available, computed tomography scan is the second choice $[22,23]$. On T1 weighted image, hematoma commonly displays iso-intensity signal within 24 hours and high-intensity signal 36 hours after symptom onset [24, 25].

Spinal angiography was not performed in the present case. It is not mandatory in the diagnosis of SSEH in acute stage, because the time spent on this procedure would deteriorate the spine compression. Therefore, the delay in taking angiography is useless, especially for the patients with progressive neurological deterioration [26]. The differential diagnosis of SSEH includes acute herniated intervertebral disc, acute ischemia of the spinal cord, epidural tumor or abscess, spondylitis, transverse myelitis, dissection aortic aneurysm, and acute myocardial infarction [2]. Early surgical treatment is the general management of SSEH [22].

At previous study concluded that the interval of preoperation is correlated with better neurological and functional recovery [10]. If the initial neurological deficits are complete, the operation should be performed within 36 hours after symptom onset. In case of incomplete neurological deficit, operation should be within 48 hours [27]. Some studies asserted that the operation within 12 hours from the initial ictus seems to be the best therapeutic window $[27,28]$. Another factor that affects the prognosis is the patient's neurologic grade. Poor initial neurologic grades predict the worse result. The shorter the progressive interval appeared, the worse the prognosis. Other factors such as age, sex, size, and position were not correlated with the postoperative outcome [11].

\section{Conclusion}

SSEH should be considered when a patient presents with symptoms of spinal cord compression after sudden back pain or chest pain. To prevent serious permanent neurologic deficit, early and correct diagnosis with timely surgical management is necessary.

\section{Ethical Considerations}

\section{Compliance with ethical guidelines}

All steps of this research were reviewed by Urmia University of Medical Sciences, ethical committee, with ethical code of $43256 / 4321$.

\section{Funding}

This article was supported by Urmia University of Medical Sciences.

\section{Conflict of interest}

The authors declared no conflict of interest.

\section{Acknowledgements}

We really appreciate Aydin Kazempoor and Saber Ramezanpoor for reviewing this article.

\section{References}

[1] Alexiadou-Rudolf C, Ernestus Rl, Nanassis K, Lanfermann H, Klug N. Acute nontraumatic spinal epidural hematomas: An important differential diagnosis in spinal emergencies. Spine. 1998; 23(16):1810-3. [DOI:10.1097/00007632-199808150-00018]

[2] Baek BS, Hur JW, Kwon KY, Lee HK. Spontaneous spinal epidural hematoma. Journal of Korean Neurosurgical Society. 2008; 44(1):40-2 [DOI:10.3340/jkns.2008.44.1.40]

[3] Bruyn GW, Bosman NJ. Spinal extradural hematoma. In: Vinken PJ, Bruyn GW, Braakman R (eds.), Handbook of Clinical Neurology. Amsterdam: North-Holland Publishing; 1976.

[4] Groen RJ, Ponssen H. The spontaneous spinal epidural hematoma: A study of the etiology. Journal of the Neurological Sciences. 1990; 98(23):121-38. [DOI:10.1016/0022-510X(90)90253-J]

[5] Rose KD, Croissant PD, Parliament CF, Levin MB. Spontaneous spinal epidural hematoma with associated platelet dysfunction from excessive garlic ingestion: A case report. Neurosurgery. 1990; 26(5):880-2. [DOI:10.1227/00006123-199005000-00026]

[6] Kirazli Y, Akkoc Y, Kanyilmaz S. Spinal epidural hematoma associated with oral anticoagulation therapy. American Journal of Physi- 
cal Medicine \& Rehabilitation. 2004; 83(3):220-3 [DOI:10.1097/01. PHM.0000107498.91919.44] [PMID]

[7] Jackson R. A case of spinal apoplexy. Lancet. 1869; 94(2392):5-6. [DOI:10.1016/S0140-6736(02)67624-X]

[8] Kreppel D, Antoniadis G, Seeling W. Spinal hematoma: A literature survey with meta analysis of 613 patients. Neurosurgical Review. 2003; 26(3):1-49. [DOI:10.1007/s10143-002-0224-y] [PMID]

[9] Holtås S, Heiling M, Lönntoft M. Spontaneous spinal epidural hematoma: Findings at MR imaging and clinical correlation. Radiology. 1996; 199(2):409-13. [DOI:10.1148/radiology.199.2.8668786]

[10] Groen RJ. Operative treatment of spontaneous spinal epidural hematomas: A study of the factors determining postoperative outcome. Neurosurgery. 1996; 39(3):494-508. [DOI:10.1227/00006123-19960900000012]

[11] Jaeger M, Jeanneret B, Schaeren S. Spontaneous spinal epidural haematoma during Factor Xa inhibitor treatment (Rivaroxaban). European Spine Journal. 2012; 21(4):433-5. [DOI:10.1007/s00586-011-2003-3] [PMID] [PMCID]

[12] Gopalkrishnan CV, Dhakoji A, Nair S. Spontaneous cervical epidural hematoma of idiopathic etiology: Case report and review of literature. The Journal of Spinal Cord Medicine. 2012; 35(2):113-7. [DOI:10.1179/2045 772312Y.0000000001] [PMID] [PMCID]

[13] Sarubbo S, Garofano F, Maida G, Fainardi E, Granieri E, Cavallo MA Spontaneous and idiopathic chronic spinal epidural hematoma: Two case reports and review of the literature. European Spine Journal. 2009; 18(11):1055-61. [DOI:10.1007/s00586-009-1175-6] [PMID] [PMCID]

[14] Groen RJ, Grobbelaar M, Muller CJ, Van Solinge G, Verhoof O, Du Toit $\mathrm{DF}$, et al. Morphology of the human internal vertebral venous plexus: $\mathrm{A}$ cadaver study after latex injection in the 21-25-week fetus. Clinical Anatomy: The Official Journal of the American Association of Clinical Anatomists and the British Association of Clinical Anatomists. 2005; 18(6):397403. [DOI:10.1002/ca.20153]

[15] Groen RJ, Groenewegen HJ, van Alphen HA, Hoogland PV. Morphology of the human internal vertebral venous plexus: A cadaver study after intravenous araldite CY 221 injection. The Anatomical Record. 1997; 249(2):285-94. [PMID]

[16] Guzel A, Simsek O, Larasalihoglu S, Kucukugurluoglu Y, Acunas B, Tosun A, et al. Spontaneous spinal epidural hematoma after seizure: A case report. Clinical Pediatrics. 2007; 46(3):263-5. [DOI:10.1177/0009922806289427] [PMID]

[17] Liu Z, Jiao Q, Xu J, Wang X, Li S, You C. Spontaneous spinal epidura hematoma: Analysis of 23 cases. Surgical Neurology. 2008; 69(3):253-60. [DOI:10.1016/j.surneu.2007.02.019] [PMID]

[18] Solheim O, Jorgensen JV, Nygaard OP. Lumbar epidural hematoma af ter chiropractic manipulation for lower-back pain: Case report. Neurosurgery. 2007; 61(1):E170-1. [DOI:10.1227/01.neu.0000279740.61048. e2]

[19] Marx JA, Hockberger RS, Walls RM, Adams GA. Rosen's emergency medicine: Concepts and clinical practice. Philadelphia: Mosby Incorporated; 2010.

[20] Chan DT, Boet R, Poom WS, Yap F, Chan YL. Spinal shock in spontaneous cervical spinal epidural hematoma. Acta Neurochirurgica. 2004; 146(10):1161-2. [DOI:10.1007/s00701-004-0347-8] [PMID]

[21] Binder DK, Sonne DC, Lawton MT. Spinal epidural hematoma. Neurosurgury. 2004; 14(1):51-9. [DOI:10.1097/00013414-200403000-00009]
[22] Matsumura A, Namikawa T, Hashimoto R. Clinical management for spontaneous spinal epidural hematoma: Diagnosis and treatment. Spine. 2008; 8(3):534-7. [DOI:10.1016/j.spinee.2007.01.009] [PMID]

[23] Riaz S, Jiang H, Fox R, Lavoie M, Mahood JK. Spontaneous spinal epidural hematoma causing Brown-Sequard syndrome: Case report and review of the literature. The Journal of Emergency Medicine. 2007; 33(3):241-4. [DOI:10.1016/j.jemermed.2007.02.032] [PMID]

[24] Carlier R, Engerand S, Lamer S, Vallee C, Bussel B, Polivka M. Foramial epidural extraosseous cavernous hemangioma of the cervical spine: A case report. Spine. 2000; 25(5):629-31. [DOI:10.1097/00007632200003010-00016]

[25] Chen CJ, Hsu WC. Imaging findings of spontaneous spinal epidural hematoma. Journal of the Formosan Medical Association= Taiwan yi zhi. 1997; 96(4):283-7. [PMID]

[26] Qiu W, Sun W, Guo C, Wu Z, Ding M, Shen H. Diagnosis and microsurgery of symptomatic spontaneous spinal epidural hematoma. Irish Journal of Medical Science. 2011; 180(1):241-5. [DOI:10.1007/s11845010-0533-z] [PMID]

[27] Lawton MT, Porter RW, Heiserman JE, Jacobowitz R, Sonntag VK, Dickman CA. Surgical management of spinal epidural hematoma: Relationship between surgical timing and neurological outcome. Journal of Neurosurgery. 1995; 83(1):1-7. [DOI:10.3171/ jns.1995.83.1.0001] [PMID]

[28] Ghasemi AA. [Spantaneuse epidural hematoma of spinal cord: Case report and review of article [Persian]. Urumia Medical Science Journal. 2010; 22(1):71-4. 
